\title{
Protection of Cardiac Cell-to-Cell Coupling Attenuate Myocardial Remodeling and Proarrhythmia Induced by Hypertension
}

\author{
T. EGAN BENOVA ${ }^{1}$, B. SZEIFFOVA BACOVA ${ }^{1}$, C. VICZENCZOVA ${ }^{1}$, E. DIEZ $^{2}$, \\ M. BARANCIK ${ }^{1}$, N. TRIBULOVA ${ }^{1}$ \\ ${ }^{1}$ Institute for Heart Research, Slovak Academy of Sciences, Bratislava, Slovakia, ${ }^{2}$ Institute of \\ Physiology, Faculty of Medicine, National University of Cuyo, Argentina
}

Received June 1, 2016

Accepted June 15, 2016

\section{Summary}

Gap junction connexin channels are important determinants of myocardial conduction and synchronization that is crucial for coordinated heart function. One of the main risk factors for cardiovascular events that results in heart attack, congestive heart failure, stroke as well as sudden arrhythmic death is hypertension. Mislocalization and/or dysfunction of specific connexin-43 channels due to hypertension-induced myocardial remodeling have been implicated in the occurrence of lifethreatening arrhythmias and heart failure in both, humans as well as experimental animals. Recent studies suggest that downregulation of myocardial connexin-43, its abnormal distribution and/or phosphorylation might be implicated in this process. On the other hand, treatment of hypertensive animals with cardioprotective drugs (e.g. statins) or supplementation with non-pharmacological compounds, such as melatonin, omega-3 fatty acids and red palm oil protects from lethal arrhythmias. The antiarrhythmic effects are attributed to the attenuation of myocardial connexin-43 abnormalities associated with preservation of myocardial architecture and improvement of cardiac conduction. Findings uncover novel mechanisms of cardioprotective (antihypertensive and antiarrhythmic) effects of compounds that are used in clinical settings. Well-designed trials are needed to explore the antiarrhythmic potential of these compounds in patients suffering from hypertension.

\section{Key words}

Hypertension • Arrhythmias • Connexin-43 • Cardioprotection

\section{Corresponding author}

T. Egan Benova, Institute for Heart Research, Slovak Academy of Sciences, Dúbravská cesta 9, P.O.Box 104, 84005 Bratislava, Slovakia. E-mail: tamara.benova@savba.sk

\section{Introduction}

Large cohort studies and interventional trials consistently show a strong positive association between hypertension and cardiovascular diseases (CVD). Hypertension is a multifactorial process and it is known that lowering blood pressure significantly improves cardiovascular health. Genetic, epigenetic and environmental factors contribute to essential hypertension (Kunes and Zicha 2009, Zicha et al. 2015) and sympathetic nervous system plays a major role in the maintenance of hypertension. In addition, association with other metabolic alterations and obesity potentiate sympathetic activation in hypertension that is accompanied by oxidative stress and inflammation (Hirooka 2011). Activation of the renin-angiotensinaldosterone system contributes to altered insulin/IGF-1 (Insulin-like growth factor 1) signaling pathways and reactive oxygen species formation resulting in endothelial dysfunction and cardiovascular diseases (Cooper et al. 2007). Likewise the incidence of metabolic syndrome in which hypertension is one of the important factors increases in the developed countries (Kunes et al. 2015). These undesired processes might be ameliorated by interventions with compounds possessing antioxidant and free radicals scavenging 
ability, e.g. melatonin, statins, adrenergic beta receptors blockers and omega-3 fatty acids (omega-3 PUFA). Patients with uncontrolled essential hypertension have elevated concentrations of superoxide anion, hydrogen peroxide, lipid peroxides, endothelin, and transforming growth factor-beta with a simultaneous decrease in endothelial nitric oxide, superoxide dismutase, vitamin E, and long-chain polyunsaturated fatty acids (Wolf 2000, Borghi and Cicero 2006, Rodrigo et al. 2011). The implication of redox signaling and lower omega-3 index is suggested in the pathogenesis of essential hypertension in animal models as well (Bačová et al. 2013, Majzunova et al. 2013). Omega-3 PUFA exhibit wide-ranging biological actions (Borghi and Cicero 2006) that include the regulation of renal sodium excretion and vasomotor tone, partly by decreasing the production of vasocostrincting and anti-inflammatory eicosanoids. Omega-3 PUFA also activate the parasympathetic nervous system. It is proposed that the availability of adequate amount of omega-3 PUFA during the critical periods of growth prevents the development of hypertension in adulthood (Das 2004).

Hypertension is a major risk factor for cardiovascular injury resulting in heart attack, congestive heart failure, stroke as well as sudden arrhythmic death (Diamond and Phillips 2005, Zanchetti 2011). The latter is associated with myocardial structural remodeling that follows hypertension, such as hypertrophy and fibrosis. This remodeling is accompanied by changes in expression, distribution and function of cell membrane ion channels, intercellular gap-junction connexin-43 (Cx43) channels, $\mathrm{Ca}^{2+}$-cycling proteins, and extracellular matrix composition (Hill 2003, Tribulova et al. 2003, Kostin et al. 2004, Teunissen et al. 2004). Remodeling predisposes to arrhythmogenic mechanisms including early or delayed after-depolarization and re-entry of excitation, facilitating life-threatening ventricular tachycardia (VT) and ventricular fibrillation (VF).

\section{Hypertension-related gap junctions and connexin-43 remodeling}

Changes in cardiac workload due to pressure or volume overload induce hypertrophic growth of individual myocytes. Hypertrophy of cardiomyocytes counteracts the increased wall tension (Laplace's law), and is therefore often considered as compensated hypertrophy (Lorell and Carabello 2000). However, prolonged state of hypertrophy is accompanied by maladaptation that promotes progression into heart failure (decompensated hypertrophy). Typical ultrastructural alterations of cardiomyocytes from the left ventricle of old spontaneously hypertensive rats (frequently used model mimicking essential hypertension in humans) are demonstrated on Figure 1.
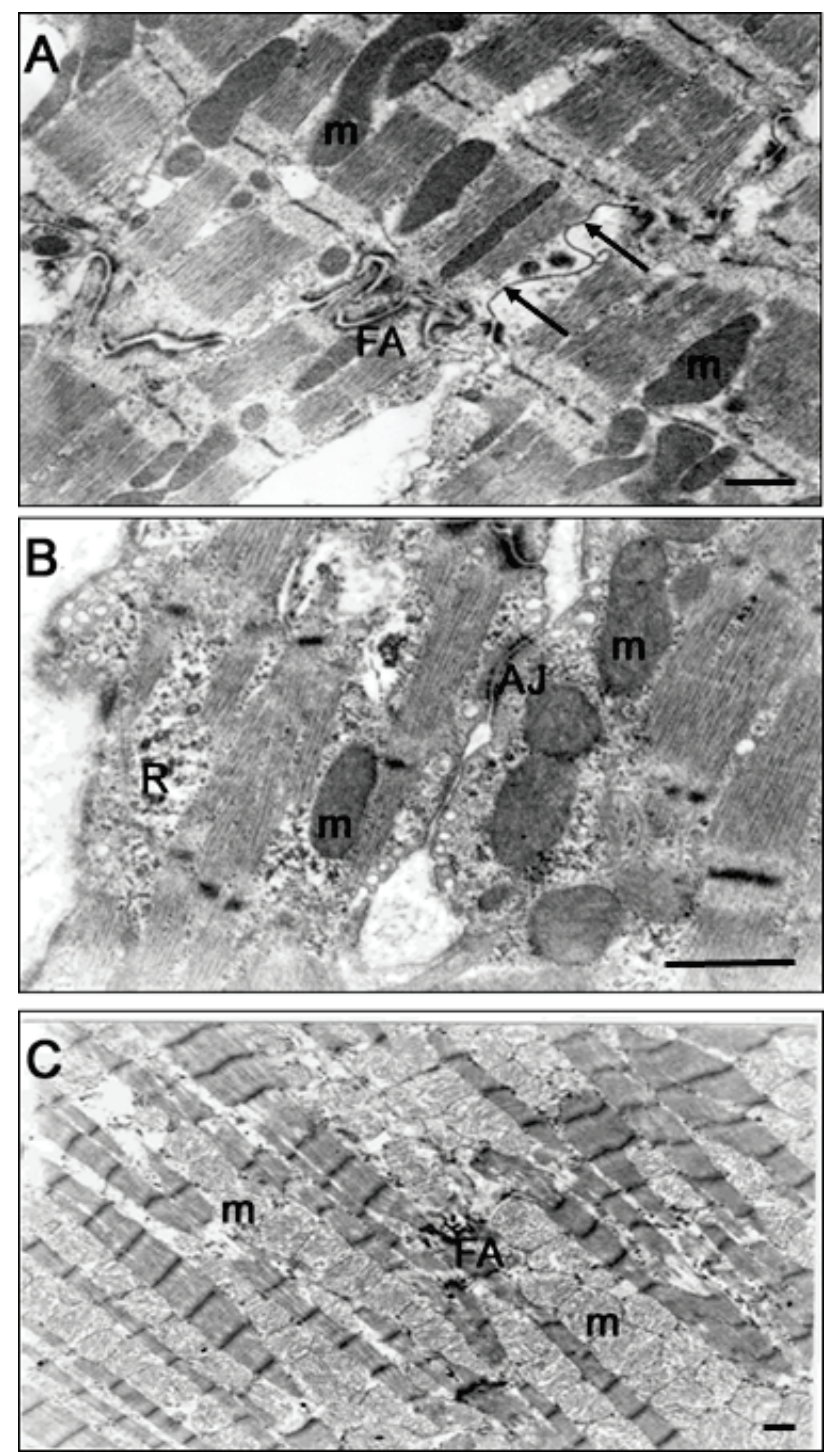

Fig. 1. Representative electron microscopic images demonstrating cardiomyocytes and intercellular junctions in left ventricles of spontaneously hypertensive rat hearts. (A) Conventional ultrastructure showing electron dense mitochondria (m), adhesive fascia adherens (FA) junctions at the intercalated disc and peripheral gap junction (arrows) on lateral sides of the cardiomyocytes. (B) Development of lateral gap junctions following formation of adhesive junctions (AJ) and high amount of ribosomes $(R)$ and dense mitochondria $(m)$ are seen in young hypertensive rat hearts at the compensated stage of hypertrophy. (C) Severely injured cardiomyocytes exhibiting edematous mitochondria, myocytolysis, pronounced reduction of adhesive fascia adherens (FA) junctions and loss of gap junctions are sporadically seen in myocardium of old hypertensive rats at the early decompensated stage of hypetrophy. Scale bar $-1 \mu \mathrm{m}$. 
The cardiac remodeling process is characterized by both, structural and electrical disorders that decrease the electrical stability of the heart (Teunissen et al. 2004, Fontes et al. 2012). A hallmark of the electrical changes with regard to impulse conduction is an impairment of electrical coupling due to abnormal expression of $\mathrm{Cx} 43-$ constituted gap junctions. Available data suggest that particularly spatial heterogeneity and severity of $\mathrm{Cx} 43$ channels dysfunction throughout myocardium affects myocardial conduction and electrical properties of the heart. In addition to structural remodeling, hypertension likewise other systemic or heart diseases and proarrhythmogenic conditions are linked with oxidative stress and/or inflammation (Rodrigo et al. 2011, Hirooka 2011, Majzunova et al. 2013). This pathology contributes to the impairment of intercellular junctions and communication due to the acceleration of $\mathrm{Cx} 43$ degradation and/or dysfunction, as well as others $\mathrm{Cx} 43$ interacting proteins (Smyth et al. 2010). Cascade events induced by hypertension resulting in an increased risk for malignant arrhythmias are demonstrated on Figure 2.

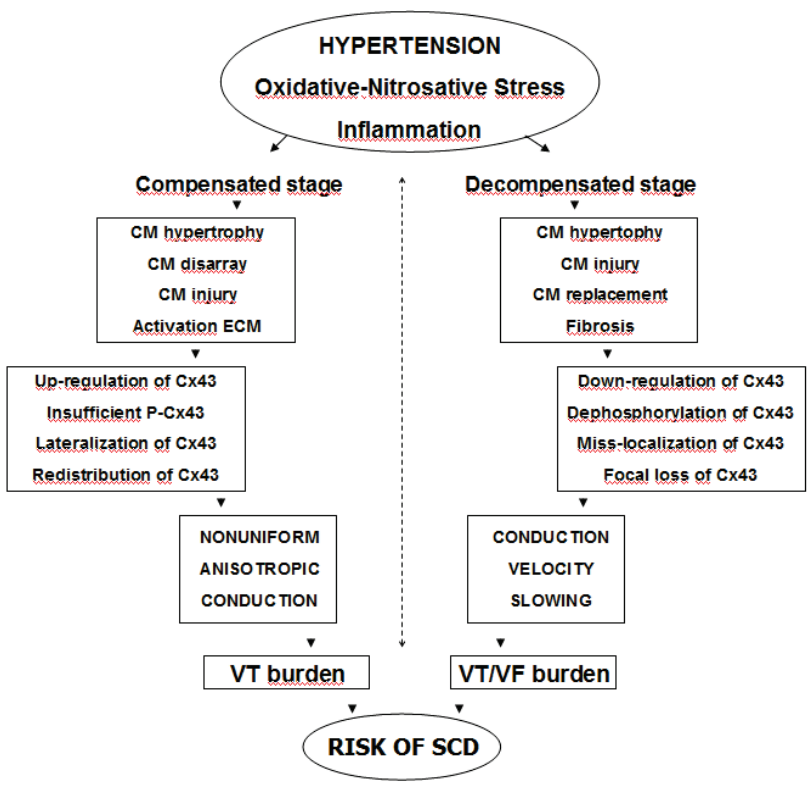

Fig. 2. Scheme showing possible myocardial alterations of cardiomyocytes as well as Cx43 expression and distribution that might increase the risk for sudden cardiac death (SCD) in spontaneously hypertensive rats and also most likely in patients suffering from essential hypertension.
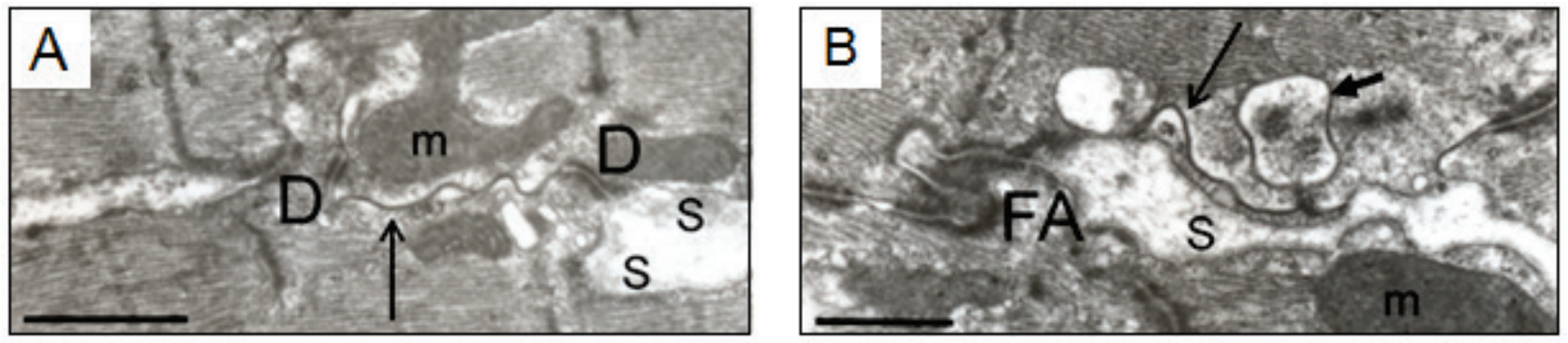

Fig. 3. Representative electron microscopic images demonstrating altered topology of myocardial gap junctions in hypertensive rat hearts. (A) Laterally situated gap junctions in the vicinity of adhesive junctions are seen in young rats frequently at compensated stage of hypertrophy. (B) Internalisation of intercalated disc related gap junctions (arrows) is often seen in old rats at decompensated stage of hypetrophy. s-sarcolemma, D - desmosome, FA - fascia adherens junction, $\mathrm{m}$ - mitochondria, scale bar - $1 \mu \mathrm{m}$.

The number, size and distribution of myocardial gap junctions change during hypertrophic heart disease. In general, $\mathrm{Cx} 43$ expression appears to be either unaltered or up-regulated during the initial and compensatory phase of hypertrophy, but always redistributed along the cardiomyocyte surface (Fig. 3). Myocardial Cx43 expression and the number of intercalated disc-related gap junctions are reduced when the hypertrophy becomes maladaptive and is accompanied by severe cardiomyocyte injury and interstitial fibrosis resulting in progression to heart failure (Teunissen et al. 2004). Kostin et al. (2004) reported that in the left ventricles of pressure-overloaded human hearts with aortic stenosis, Cx43 expression was increased in the compensated hypertrophic stage, but decreased and heterogeneously distributed throughout the ventricles in the period of decompensated hypertensive heart. The decreased expression of $\mathrm{Cx} 43$ at the protein level is accompanied by a reduction of $\mathrm{Cx} 43 \mathrm{mRNA}$, suggesting that the downregulation of $\mathrm{Cx} 43$ in hypertrophic heart disease is regulated at the transcriptional level (Curcio et al. 2011, Radosinska et al. 2013). Down-regulation and/or heterogeneous redistribution of $\mathrm{Cx} 43$ channels is often associated with abnormal conduction (Fischer et al. 2008) that facilitates arrhythmias (Fig. 2), although there seems to be a large reserve before reduced intercellular coupling becomes arrhythmogenic (Fontes et al. 2012). Interestingly, hypertrophic cardiomyopathy, the most 
common genetic disease of the myocardium, is also characterized by cardiomyocyte hypertrophy, myofibrillar disarray, fibrosis and miss-localization of $\mathrm{Cx} 43$ linked with changes in myocardial conduction and prolonged QRS interval (Calore et al. 2015). Consequently, there is a high risk of sudden arrhythmic death, especially in young adults (including competitive athletes).

In the context of myocardial remodeling and Cx43 alterations, it is important to note that microRNA-1 has an essential regulatory impact in cardiogenesis, cardiac hypertrophy and cardiac electrophysiology. The latter is due to its ability to modulate the expression levels of molecular targets that affect the electrical properties of cardiac cells. These targets are GJA1 (Gap junction alpha-1) encoding $\mathrm{Cx} 43$ and KCNJ2 (Inward rectifier potassium channel 2) encoding potassium channel proteins that determine myocardial conduction velocity and repolarization (Zhao et al. 2007). Downregulation of microRNA-1 at early stage of cardiac hypertrophy was associated with increased $\mathrm{Cx} 43$ protein levels and enhanced $\mathrm{Cx} 43$ phosphorylation. The latter correlated with displacement of $\mathrm{Cx} 43$ from the gap junctions that facilitate ventricular tachyarrhythmias (Curcio et al. 2013). In turn, it is most likely that decompensated hypertrophic stage accompanied by decrease of $\mathrm{Cx} 43$ gene transcripts and protein levels might result from up-regulation of microRNA-1. This view is supported by findings that inflammation (known to be implicated in the pathogenesis of hypertension) represses $\mathrm{Cx} 43$ expression via up-regulation of microRNA-1 and potentiates arrhythmogenesis by targeting GJA1 (Yang et al. 2007, Xu et al. 2012).

Taken together, it can be hypothesized that the prevention or attenuation of maladaptive myocardial Cx43 remodeling and dysfunction induced by hypertension could decrease the risk from arrhythmic death and heart failure (Fontes et al. 2012, Tribulova et al. 2015).

\section{The role of myocardial $\mathrm{Cx} 43$ in protecting the heart from malignant arrhythmias}

Therapy to prevent death due to arrhythmias involves invasive procedures, i.e. implantable cardioverter defibrillator to protect from sudden cardiac death when VF occurs, catheter ablation of arrhythmogenic loci and resynchronization devices for supporting myocardial synchronization and thereby reducing arrhythmia risk. Blockade of ion current by antiarrhythmic drugs is often ineffective and may even cause proarrhythmia that can increase mortality. As a result, the effort to develop new antiarrhythmic drugs directed at specific ion channels has decreased dramatically. However, mentioned invasive procedures did not prevent occurrence and recurrence of life-threatening arrhythmias. Moreover, these interventions decrease the quality of life and can also be accompanied by various complications. Therefore, novel approach in fighting arrhythmia-related sudden cardiac death and stroke is warranted. Considering the crucial role of intercellular coupling and communication to ensure synchronized myocardial contraction, it seems relevant to suggest the implication of these factors in prevention of arrhythmias.

The novel approach is based on the prevention or attenuation of development of arrhythmogenic substrates in relation to $\mathrm{Cx} 43$ channels function to reduce a risk of arrhythmia occurrence (Sovari et al. 2013, Tribulova et al. 2015). Taking into consideration events involved in a development of malignant arrhythmias, such as oxidative/nitrosative stress, myocardial hypertrophy and/or fibrosis, $\mathrm{Cx} 43$ remodeling, conduction disturbances; the action of antiarrhythmic compounds is expected to include one or more steps in cascade of events (Tribulova et al. 2015). Consistent with it, the "upstream" drug therapy is of great interest aiming to prevent or eliminate arrhythmogenic substrates and triggers. Lipid lowering and some antihypertensive drugs, as well as statins, are known to exhibit antiarrhythmic effects likely due to the attenuation of myocardial remodeling (hypertrophy, fibrosis) that affects intercellular coupling mediated by $\mathrm{Cx} 43$ channels. In addition, these pharmacological compounds exert antioxidant and anti-inflammatory efficacy. All these actions appear to preserve the adequate myocardial $\mathrm{Cx} 43$ levels and topology. Both direct and indirect salutary modulation of $\mathrm{Cx} 43$ channels function may confer protection from malignant arrhythmias. Despite the increasing number of experimental studies supporting this idea, there are still many questions to be answered by further research. The topic is challenging to address in experimental as well as clinical settings, or when considering the development of new antiarrhythmic drugs. The following section of the article thus focuses on the benefit of some non-pharmacological compounds in spontaneously hypertensive rats, a rodent model mimicking human essential hypertension. It demonstrates novel pleiotropic effects of melatonin and new mechanisms of omega-3 PUFA and antioxidant-rich red palm oil actions that are associated with the modulation of myocardial $\mathrm{Cx} 43$. 
Antihypertensive and antiarrhytmic effects of melatonin

Melatonin can reduce blood pressure i) through the direct effect on hypothalamus; ii) by its antioxidant properties that lower blood pressure; iii) by decreasing the amount of catecholamines (Sewerynek 2002). Blood pressure lowering effect of melatonin could also be mediated by its direct effect on blood vessels or by decreasing serotonin production that is crucial in the inhibition of sympathetic, and stimulation of parasympathetic system (Benova et al. 2009). Melatonin could affect changes in blood pressure also through its specific melatonin receptors localized in the peripheral vessels or in parts of central nervous system that directly participate in the control of blood pressure (Simko and Paulis 2007).

In addition to its circadian rhythm regulatory efficacy that is possibly responsible for the hypotensive effects, melatonin can modulate cellular redox state and improve the function of the cardiovascular system in pathological conditions (Dominguez-Rodriguez et al. 2010, Simko et al. 2014, Diez et al. 2015). Elderly population has reduced circulating melatonin levels (Reiter 1995, Kedziora-Kornatowska et al. 2007). Decrease of melatonin was also registered in patients suffering from primary hypertension compared with normotensive individuals (Das $\mathrm{R}$ et al. 2008). Increased melatonin concentration in elderly patients suffering from hypertension may thus be of crucial therapeutic importance. Patients suffering from coronary heart disease, the most typical complication of chronic hypertension, exhibited over five-fold lower level of serum melatonin at night compared with the control group (Brugger et al. 1995). Likewise, patients demonstrating a "non-dipping profile" of nocturnal arterial pressure exhibited decreased nocturnal melatonin secretion compared with the patients showing a "dipping profile" (Jonas et al. 2003, Zeman et al. 2005). The study by Kedziora-Kornatowska et al. (2008) confirms the benefit of melatonin supplementation on parameters of oxidative stress in elderly patients suffering from primary hypertension and suggests that melatonin supplementation can be considered as a supporting therapy in the treatment of hypertension. As demonstrated by Mozdzan et al. (2012), a significant hypotensive effect was observed in "non-dippers". Melatonin is effective in lowering blood pressure in essential hypertensive patients (Scheer et al. 2004) and in patients with nocturnal hypertension (Grossman et al.
2006). The antihypertensive effect of exogenous melatonin is reported in numerous experimental studies (Grossman et al. 2006, Simko and Paulis 2007, Simko and Pechanova 2009, Rechciński et al. 2010, Paulis et al. 2012, Benova et al. 2013).

In addition to antihypertensive effects of melatonin, in vitro and in vivo experimental studies demonstrate its acute antiarrhythmic effects (Kaneko et al. 2000, Szarszoi et al. 2001, Diez et al. 2013, Benova et al. 2015). Melatonin appears to be effective even in physiological concentrations. On the other hand, in pinealectomized rats, the arrhythmic score was substantially elevated after the coronary artery ligation when compared with untreated controls (Sahna et al. $2002 \mathrm{a}, \mathrm{b})$. In almost all of the above mentioned studies melatonin-induced cardioprotection and its antiarrhythmic effects are attributed to its free radical scavenging potential (Kaneko et al. 2000, Lee et al. 2002, Dobsak et al. 2003). Of note, melatonin has several features that make it of clinical interest. It has low toxicity, it crosses all types of biological barriers (i.e. blood-/brain barrier and placenta) and it can easily enter to all cell compartments including mitochondrias, producers of free radicals (Dobsak et al. 2003).

\section{Antihypertensive and antiarrhytmic effects of omega-3 PUFA}

Numerous studies report salutary effects of omega-3 PUFA, i.e. eicosapentaenoic acid (EPA) and docosahexaenoic acid (DHA) on CVD risk factors (Allayee et al. 2009). These effects include i) lowering of serum triglycerides by reducing of hepatic triglycerides production; ii) lowering of blood pressure by improving of endothelial cell function; iii) decreasing of platelet aggregation by reducing of prothrombotic prostanoids; iv) decreasing inflammation via reduction in 4-series leukotriene production; v) protection from arrhythmias by modulation of electrophysiological properties of cardiac myocytes (Bonafini et al. 2015). Systematic metaanalysis suggests that high doses of omega-3 PUFA ( $\sim 3 \mathrm{~g} /$ day) produce a small, but significant decrease in systolic blood pressure in older and hypertensive subjects (Cabo et al. 2012). Beneficial effects of omega-3 PUFA on CVD risk factors in children, including regulation of blood pressure during childhood and adolescence was recently reviewed (Bonafini et al. 2015).

Observational and interventional studies indicate that dietary omega-3 PUFA may be effective in preventing cardiac arrhythmias and sudden cardiac death. 
The strongest evidence suggesting an antiarrhythmic effect of omega-3 PUFA, resulting in a significant reduction of sudden cardiac death is provided in the large GISSI-Prevenzione trial (Marchioli et al. 2007). Antiarrhythmic actions observed in both clinical and experimental conditions are mostly associated with myocardial infarction or post-infarction related malignant arrhythmias. Some studies, in particular clinical trials, did not clearly demonstrate the antiarrhythmic effects of omega-3 PUFA (Rauch and Senges 2012, Rizos et al. 2012, Calò et al. 2013). To explain the discrepancy of the results, it is suggested that the effectiveness of omega-3 PUFA treatment might depend on the mechanism of cardiac arrhythmias and on the dose and route of omega-3 PUFA administration (Richardson et al. 2011). Moreover, efficacy of omega-3 PUFA supplementation in clinical trials should be adjusted to initial basal levels of omega-3 PUFA (omega-3 index) as well as medical treatment regimen of patients. The multiple mechanisms of cardioprotective and antiarrhythmic effects of omega-3 PUFA include ion channels function modulation and prevention of pressure overload related cardiac remodeling (Endo and Arita 2016).

\section{Cardioprotective and antiarrhythmic effects of red palm oil}

The link between dietary fats and cardiovascular diseases has initiated a growing interest in a dietary red palm oil (RPO) research. RPO is obtained from the orange-red mesocarp of the fruit of a tropical plant known as oil palm (Elaeis guineensis) (Edem 2009). Besides unsaturated and saturated fatty acids, it contains high concentration of antioxidants such as vitamin A (carotenes), pro-vitamin E - namely tocotrienols, tocopherols, coenzyme Q10 and lycopene (Edem 2002, Das S et al. 2008, Van Rooyen et al. 2008). Despite of its high content of saturated fatty acid, RPO intake does not promote vascular disease. On the contrary, the benefits of RPO on health include reduction in the risk of arterial thrombosis and/or atherosclerosis, platelet aggregation, blood pressure (Edem 2002), inhibition of endogenous cholesterol biosynthesis and a reduction in oxidative stress (Das S et al. 2008). Oxidative stress and the severity or progression of disease has stimulated further interest in the potential role of RPO (a cocktail of natural antioxidants) to improve redox status. Experimental studies suggest that the cardioprotective effects of RPO may not only be due to the high antioxidant content but could also be mediated by the ability of RPO to modulate signaling events during ischemia and reperfusion (Van Rooyen et al. 2008, Engelbrecht et al. 2009). The cardioprotective effects of the tocotrienol rich fraction of RPO have been attributed to its ability to modulate the Akt signaling, thus generating a survival signal during reperfusion (Das S et al. 2008). Another study has also shown that beneficial effects of RPO are partially mediated by the phosphatidylinositol 3-kinase (PI3-K) and protein kinase B (Akt) signaling pathway (Engelbrecht et al. 2009). These findings strongly suggest that PI3K-Akt pathway may play an important role in the RPO-induced cardioprotection, however, this evidence is circumstantial since PI3-K has several downstream targets other than Akt. To elucidate the importance of Akt on post ischemic functional recovery in RPO supplemented animals, Akt would have to be specifically inhibited. Furthermore, RPO supplementation is associated with an increased dual phosphorylation of Akt on Ser473 and Thr308 residues indicating that optimal activation of Akt requires phosphorylation on both Ser473 and Thr308 residues (Esterhuyse et al. 2006, Engelbrecht et al. 2006). Recent experimental studies demonstrated that RPO supplementation offers protection against ischemia/ reperfusion injury by improving cardiac output recovery. Evidence strongly suggests that mitogen activated protein kinases (MAPKs), NO-cGMP and prosurvival PI3K-Akt signaling pathway may be involved (Engelbrecht et al. 2006, 2009, Van Rooyen et al. 2008, Bester et al. 2010, Szucs et al. 2011). Further studies are thus needed to explore the novel cellular and molecular mechanisms that might be involved in RPO-related cardioprotection. Data indicating the antiarrhythmic potential of RPO are rare, but according to the recent study (Bačová et al. 2013), the increased susceptibility of hyperthyroid rats to malignant arrhythmias is partially ameliorated by supplementation with RPO and this effect is related mainly to the up-regulation of $\mathrm{Cx} 43$ and PKCE.

\section{Modulation of myocardial $\mathrm{Cx} 43$ expression by melatonin}

In addition to antiarrhythmic effects of acute administration of melatonin in the setting of ischemia/ reperfusion, its antiarrhythmic efficacy has been recently demonstrated in spontaneously hypertensive rats after long-term administration (Benova et al. 2013). Several studies showed that compared to normotensive rats the spontaneously hypertensive rats are much prone to develop VF (Tribulova et al. 2015). Consistently with this, the threshold to electrically inducible VF is 
significantly lower in hypertensive versus normotensive rats, but it is increased in response to melatonin treatment. This antiarrhythmic effect of melatonin is associated with the enhancement of myocardial $\mathrm{Cx} 43$ gene transcription (Benova et al. 2013) as well as the total levels of $\mathrm{Cx} 43$ protein and its functional phosphorylated forms in hypertensive, and to a lesser extent in normotensive Wistar rat hearts. Elevated $\mathrm{Cx} 43$ phosphorylation could be in part attributed to increased levels of $\mathrm{PKC \varepsilon}$ isoform resulting from melatonin treatment. Moreover, Cx43 immunofluorescence labeling and quantitative image analysis reveale the attenuation of abnormal Cx43 distribution and enhanced myocardial Cx43-positive signal in hypertensive rats treated with melatonin. These findings strongly indicate that melatonin may modulate $\mathrm{Cx} 43$ expression and distribution in the remodeled heart of hypertensive rats.

However, molecular mechanisms that govern melatonin's effects on myocardial $\mathrm{Cx} 43$ remain to be elucidated. It has been reported that melatonin up-regulates Cx43 (mRNA and protein) and enhances cell-to-cell coupling in human myometrial smooth muscle cells via $\mathrm{MT}_{2}$ receptor in $\mathrm{PKC}$-dependent manner (Sharkey et al. 2009). It is therefore proposed that melatonin activates phospholipase $\mathrm{C}$ followed by generation of inositol triphosphate and diacylglycerol. The latter activates $\mathrm{PKC}$, which can affect transcription factors c-Fos and c-Jun that are important in the regulation of $\mathrm{Cx} 43$ expression in myometrial cells (Mitchell and Lye 2001). Further studies are required to explore whether this pathway is involved in the up-regulation of $\mathrm{Cx} 43$ in the heart muscle as well. The cardioprotective and antiarrhythmic effects of acute melatonin treatment in the context of ischemia/ reperfusion were mainly attributed to its antioxidant and free radicals scavenging activity. It is most likely that these cardioprotective actions of melatonin are involved in the condition of oxidative stress induced by hypertension. Consequently, it might result in preservation of myocardial $\mathrm{Cx} 43$ proteins and protection from its down-regulation. Melatonin may be classified as a naturally occurring, mitochondrially targeted antioxidant (Reiter et al. 2014) and this fact is important when considering the most recent studies (Sovari et al. 2013, Yang et al. 2014) showing that arrhythmias could be prevented by mitochondrially targeted antioxidants rather than general antioxidants. It also seems possible that melatonin could protect myocardial $\mathrm{Cx} 43$ via inhibiting the activity of cyclooxygenase 2 and inducible NO synthase caused by chronic inflammation (Deng et al.
2006) which would lead to its downregulation. Some of the hypothetical mechanisms on the modulation of cardiac Cx43 channels and protection from malignant arrhythmias by melatonin are depicted on Figure 4.

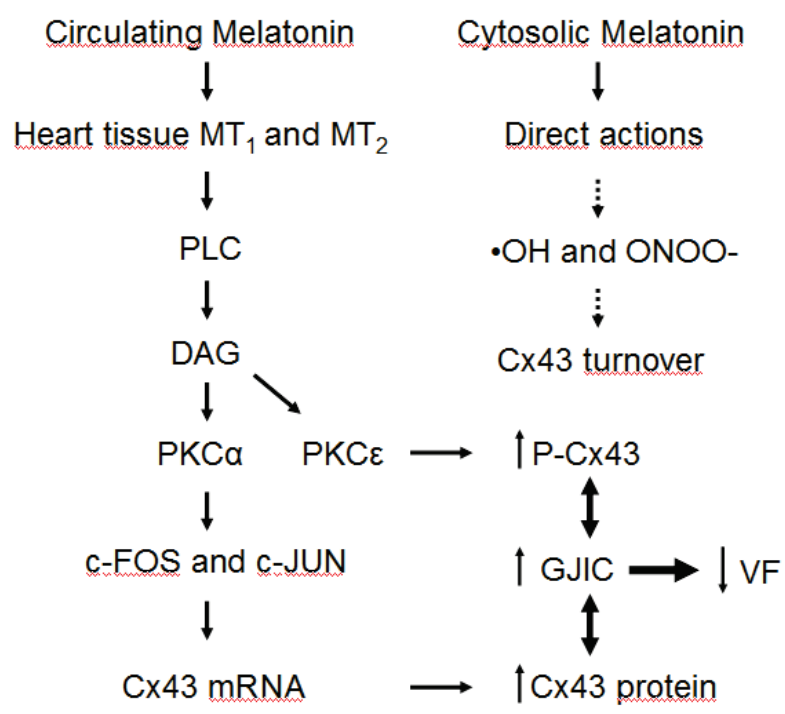

Fig. 4. Proposed mechanisms of melatonin action on myocardial Cx43 expression and distribution in spontaneously hypertensive rat heart. Circulating melatonin via its receptors, $\mathrm{MT}_{1}$ and $\mathrm{MT}_{2}$, activates phospholipase C (PLC) followed by production of diacylglycerol (DAG), which activates protein kinase $C$ (PKC). PKC $\varepsilon$ by phosphorylation of $\mathrm{Cx} 43$ (P-Cx43) can modulate the channel's function, as well as its myocardial distribution and subsequently gap junctional intercellular communication (GJIC). Activation of PKCa also affects transcription factors c-Fos and c-Jun, which bind to conserved activator protein-1 in the promoter region of $\mathrm{C} \times 43$ and hence can increase $\mathrm{C} \times 43$ expression. In addition, melatonin exhibits receptor-independent actions due to its ability to scavenge free radicals. Free radicals enhance degradation of $\mathrm{Cx} 43$ and melatonin can attenuate this process and preserve myocardial Cx43 levels. Altogether, protection of functional $\mathrm{C} \times 43$ by melatonin can affect GJIC and improve electrical stability resulting in a decrease of inducible VF.

\section{Modulation of myocardial Cx43 expression by omega-3 PUFA}

A direct renin inhibitor, aliskiren, and dietary omega-3 PUFAs attenuate electrical remodeling in reninangiotensin transgenic rats (another model that mimics human hypertension) most likely due to the restoration of the normal topology of $\mathrm{Cx} 43$ (Fischer et al. 2008). Both treatments also reduce the QRS and QT interval, suggesting an improvement in conduction that could be attributed to reduced fibrosis and to the elimination of lateral distribution of $\mathrm{Cx} 43$. The induction of tachyarrhythmias also declines. In addition, aliskiren and omega-3 PUFA prevent hypertension related inflammation that is generally known to down-regulate Cx43 (Reiffel and McDonald 2006). 
The antiarrhythmic effects of both omega-3 PUFA and atorvastatin (a hypolipidemic drug with antiinflamatory and antioxidant properties) are demonstrated in hereditary hypertriglyceridemic rats with elevated blood pressure (Bacova et al. 2010). The decrease in VF inducibility is associated with the suppression of hyper-phosphorylation of $\mathrm{Cx} 43$ and the restoration of its normal myocardial topology. Electron microscopic examination reveals that these agents improve the structural integrity of mitochondria, plasma membrane and intercellular junctions when compared to untreated diseased rats. This membrane protective effect may be partially explained by changes in membrane composition (Nair et al. 1997), such as increased incorporation of omega-3 PUFA and decreased cholesterol levels due to treatments. It would be interesting to find out whether atorvastatin, likewise omega-3 PUFA, affects properties of ion and $\mathrm{Cx} 43$ channels, as well as myocardial conduction, for the purpose of better understanding of its antiarrhythmic effects in relation to myocardial $\mathrm{Cx} 43$ alterations. Protection from VF due to intake of omega-3 PUFA (i.e. DHA and EPA) and the implication of myocardial Cx43, are demonstrated in a study (Radosinska et al. 2013) using young (compensated stage of hypertrophy) and old spontaneously hypertensive rats (early decompensated stage of hypertrophy). Findings show that omega-3 PUFA intake normalizes myocardial Cx43 mRNA levels in old rats, and $\mathrm{Cx} 43$ protein expression as well as its functional phosphorylated status in both, young and old hypertensive animals. Enhanced Cx43 phosphorylation may in part be attributed to PKC- $\varepsilon$ that is up-regulated by omega-3 PUFA. The treatment significantly eliminates abnormal Cx43 distribution, diminishes the internalization of gap junctions and improves ultrastructure (integrity) of mitochondria in cardiomyocytes of hypertensive rats. These findings clearly indicate that modulation of $\mathrm{Cx} 43$ channels function and myocardial cell-to-cell coupling by omega-3 PUFA might be possible.

Nevertheless, the question arises as to how omega-3 PUFA affect myocardial Cx43 expression and its phosphorylation. It is known that omega-3 PUFA are ligands for the nuclear transcription factor, peroxisome proliferator-activated receptor (PPAR). It is also known that omega-3 PUFA might regulate numerous gene expression and consequently intracellular pathways involved in protein expression and phosphorylation (Deckelbaum et al. 2006, Baum et al. 2012). The antiarrhythmic properties of omega-3 PUFA may also include the regulation of membrane ion current densities and intracellular $\mathrm{Ca}^{2+}$ handling (Den Ruijter 2007). The proposed mechanisms for omega-3 PUFA that could lead to the down-regulation and mislocalization of $\mathrm{Cx} 43$ are demonstrated on Figure 5. Activation of these mechanisms could lead to suppression in the incidence of life-threatening arrhythmias, hence, the discovery of omega-3 PUFA signaling pathways linked to $\mathrm{Cx} 43$ modulation may reveal new candidates for the development of novel antiarrhythmic drugs.

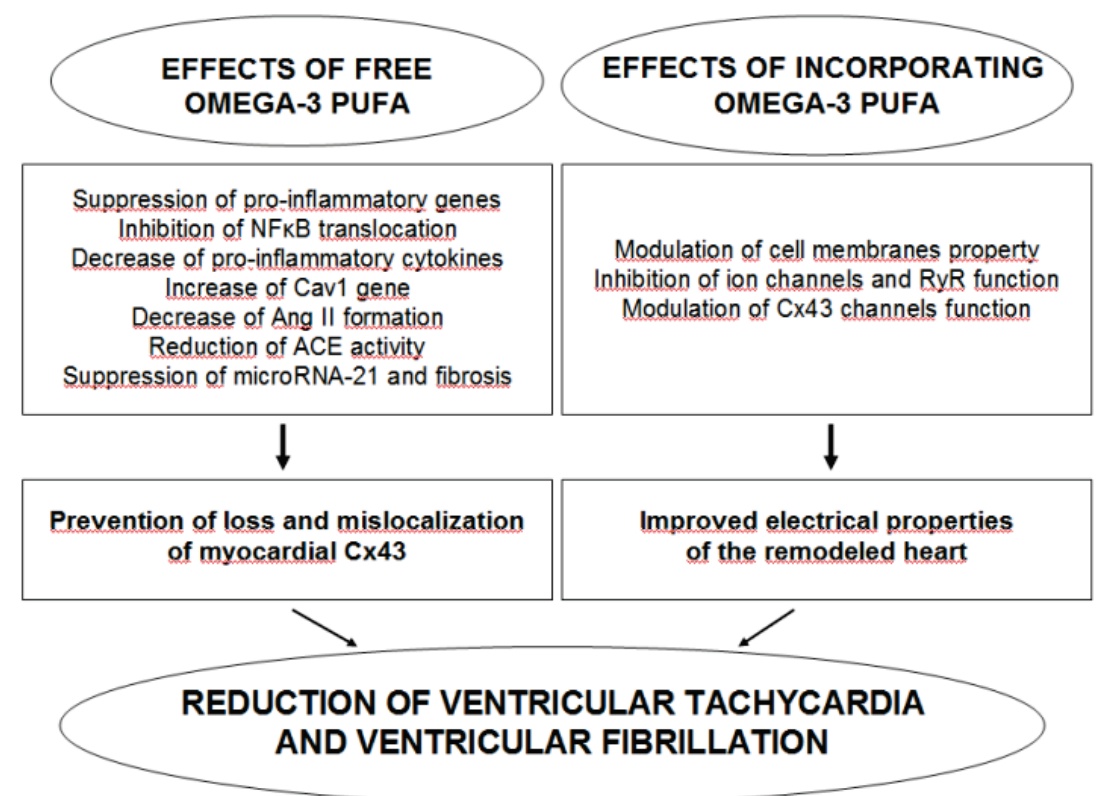

Fig. 5. Diagram for the proposed mechanisms of omega-3 PUFA that could prevent downregulation and mislocalization of cardiac Cx43. Consequently, it could lead to a reduction in the incidence of lifethreatening arrhythmias. 


\section{Modulation of myocardial $\mathrm{Cx43}$ by red palm oil}

It has been, for the first time, demonstrated that there is an up-regulation of myocardial $\mathrm{Cx} 43$ and suppression of PKC $\varepsilon$ activation in response to RPO supplementation of male, adult spontaneously hypertensive rats (Bačová et al. 2012) when compared to control rats. In this study, $\mathrm{Cx} 43-\mathrm{mRNA}$, total $\mathrm{Cx} 43$ proteins, and its phosphorylated forms are elevated due to RPO treatment. Moreover, the disordered localization of Cx43 is attenuated in the left ventricle of RPO-fed hypertensive rats compared with untreated rats. These alterations are associated with the suppression of early post-ischemic-reperfusion-related VT and electrically inducible VF. The effects were also linked to the improvement in functional recovery of the heart during post-ischemic reperfusion. However, the treatment dose of RPO (200 mg/day for 5 weeks) causes downregulation of myocardial $\mathrm{Cx} 43$ in normotensive age-matched rats which results in poor arrhythmia protection and thus suggests overdosing of RPO in healthy rats. Findings indicate that hypertensive rats can benefit from RPO intake, particularly because of its apparent antiarrhythmic effects. This protection can be, in part, attributed to up-regulation of myocardial $\mathrm{Cx} 43$ but not PKC $\varepsilon$ activation. In addition, RPO supplementation reduced blood pressure in hypertensive rats and blood glucose in both hypertensive and normotensive rats. Taken together, the results indicate that hypertensive rats benefit from RPO supplementation, particularly due to its apparent antiarrhythmic and postischemic-reperfusionrelated cardioprotective effects that can be, in part, explained by up-regulation of myocardial $\mathrm{Cx} 43$. This view is supported by findings that down-regulation of Cx43 in response to RPO intake of healthy normotensive rats is associated with poor antiarrhythmic effect.

\section{Conclusions and perspectives}

Data included in this comprehensive article suggest that attenuation of hypertension-induced abnormal and/or restoration of normal myocardial expression and distribution of $\mathrm{Cx} 43$ as well as enhancement of its functional phosphorylated forms along with positive modulation of PKC signaling by melatonin, omega-3 fatty acids and red palm oil may be crucial in their antiarrhythmic mechanisms. Despite "optimal" therapy of patients suffering from hypertension, there is still urgent need for the prevention of severe rhythm disorders. In view of many missed potential targets for preventing adverse myocardial remodeling, it appears that beneficial modulation of $\mathrm{Cx} 43$ by melatonin, omega- 3 fatty acids and red palm oil might be a useful approach in current therapy. A strong body of evidence supports the prophylactic use of these nonpharmacological compounds to minimize cardiovascular risk and sudden arrhythmic death. A novel approach is needed since despite a plethora of available treatment options, a substantial portion of the hypertensive population has uncontrolled blood pressure. Future studies should elucidate more detailed mechanisms of myocardial $\mathrm{Cx} 43$ modulation in the context of electrical properties of the heart in response to treatment of hypertension. Of note, according to the recent study by Care et al. (2016), the supplementation by resveratrol during gestational and post-gestational periods was suggested for the treatment of essential hypertension in the offspring. It is challenging to explore postgestational effects of gestational intake of melatonin and omega-3 fatty acids on myocardial $\mathrm{Cx} 43$.

\section{Conflict of Interest}

There is no conflict of interest.

\section{Acknowledgements}

This study was supported by APVV 0348/12, VEGA 2/0076/16, 2/0167/15 and SKS grants.

\section{References}

ALLAYEE H, ROTH N, HODIS HN: Polyunsaturated fatty acids and cardiovascular disease: implications for nutrigenetics. J Nutrigenet Nutrigenomics 2: 140-148, 2009.

BACOVA B, RADOSINSKA J, KNEZL V, KOLENOVA L, WEISMANN P, NAVAROVA J, BARANCIK M, MITASIKOVA M, TRIBULOVA N: Omega-3 fatty acids and atorvastatin suppress ventricular fibrillation inducibility in hypertriglyceridemic rat hearts: implication of intracellular coupling protein, connexin-43. J Physiol Pharmacol 61: 717-723, 2010. 
BAČOVÁ B, RADOŠINSKÁ J, VICZENCZOVÁ C, KNEZL V, DOSENKO V, BEŇOVÁ T, NAVAROVÁ J, GONÇALVESOVÁ E, VAN ROOYEN J, WEISMANN P, SLEZÁK J, TRIBULOVÁ N: Up-regulation of myocardial connexin- 43 in spontaneously hypertensive rats fed red palm oil is most likely implicated in its anti-arrhythmic effects. Can J Physiol Pharmacol 90: 1235-1245, 2012.

BAČOVÁ B, SEČ P, RADOŠINSKÁ J, CERTÍK M, VACHULOVÁ A, TRIBULOVÁ N: Lower omega-3 index is a marker of increased propensity of hypertensive rat heart to malignant arrhythmias. Physiol Res 62: 201-208, 2013.

BAUM JR, DOLMATOVA E, TAN A, DUFFY HS: Omega 3 fatty acid inhibition of inflammatory cytokine-mediated connexin43 regulation in the heart. Front Physiol 3: 1-8, 2012.

BENOVA M, HERICHOVA I, STEBELOVA K, PAULIS L, KRAJCIROVICOVA K, SIMKO F, ZEMAN M: Effect of L-NAME-induced hypertension on melatonin receptors and melatonin levels in the pineal gland and the peripheral organs of rats. Hypertens Res 32: 242-247, 2009.

BENOVA T, VICZENCZOVA C, RADOSINSKA J, BACOVA B, KNEZL V, DOSENKO V, WEISMANN P, ZEMAN M, NAVAROVA J, TRIBULOVA N: Melatonin attenuates hypertension-related proarrhythmic myocardial maladaptation of connexin 43 and propensity of the heart to lethal arrhythmias. Can J Physiol Pharmacol 91: 633-639, 2013.

BENOVA T, KNEZL V, VICZENCZOVA C, BACOVA BS, RADOSINSKA J, TRIBULOVA N: Acute antifibrillating and defibrillating potential of atorvastatin, melatonin, eicosapentaenoic acid and docosahexaenoic acid demonstrated in isolated heart model. J Physiol Pharmacol 66: 83-89, 2015.

BESTER DJ, KUPAI K, CSONT T, SZUCS G, CSONKA C, ESTERHUYSE AJ, FERDINANDY P, VAN ROOYEN J: Dietary red palm oil supplementation reduces myocardial infarct size in an isolated perfused rat heart model. Lipids Health Dis 9: 64, 2010.

BONAFINI S, ANTONIAZZI F, MAFFEIS C, MINUZ P, FAVA C: Beneficial effects of omega-3 PUFA in children on cardiovascular risk factors during childhood and adolescence. Prostaglandins Other Lipid Mediat 120: 72-79, 2015.

BORGHI C, CICERO AF: Omega-3 polyunsaturated fatty acids: their potential role in blood pressure prevention and management. Heart Int 2: 98-105, 2006.

BRUGGER P, MARKTL W, HEROLD M: Impaired nocturnal secretion of melatonin in coronary heart disease. Lancet 345: 1408, 1995.

CABO J, ALONSO R, MATA P: Omega-3 fatty acids and blood pressure. Br J Nutr 107: S195-S200, 2012.

CALÒ L, MARTINO A, TOTA C: The anti-arrhythmic effects of n-3 PUFAs. J Int Cardiol 170: S21-S27, 2013.

CALORE C, ZORZI A, CORRADO D: Clinical meaning of isolated increase of QRS voltages inhypertrophic cardiomyopathy versus athlete's heart. J Electrocardiol 48: 373-379, 2015.

CARE AS, SUNG MM, PANAHI S, GRAGASIN FS, DYCK JRB, DAVIDGE ST, BOURQUE SL: Perinatal resveratrol supplementation to spontaneously hypertensive rat dams mitigates the development of hypertension in adult offspring. Hypertension 67: 1038-1044, 2016.

COOPER SA, WHALEY-CONNELL A, HABIBI J, WEI Y, LASTRA G, MANRIQUE C, STAS S, SOWERS JR: Renin-angiotensin-aldosterone system and oxidative stress in cardiovascular insulin resistance. Am J Physiol Heart Circ Physiol 293: 2009-2023, 2007.

CURCIO A, TORELLA D, IACONETTI C, PASCERI E, SABATINO J, SORRENTINO S, GIAMPÀ S, MICIELI M, POLIMENI A, HENNING BJ, LEONE A, CATALUCCI D, ELLISON GM, CONDORELLI G, INDOLFI C: MicroRNA-1 downregulation increases connexin 43 displacement and induces ventricular tachyarrhythmias in rodent hypertrophic hearts. PLoS One 8: e70158, 2013.

DAS R, BALONAN L, BALLARD HJ, HO S: Chronic hypoxia inhibits the antihypertensive effect of melatonin on pulmonary artery. Int J Cardiol 126: 340-345, 2008.

DAS S, LEKLI I, DAS M, SZABO G, VARADI J, JUHASZ B, BAK I, NESARETAM K, TOSAKI A, POWELL SR, DAS DK: Cardioprotection with palm oil tocotrienols: comparison of different isomers. Am J Physiol Heart Circ Physiol 294: 970-978, 2008.

DAS UN: Long-chain polyunsaturated fatty acids interact with nitric oxide, superoxide anion, and transforming growth factor-beta to prevent human essential hypertension. Eur J Clin Nutr 58: 195-203, 2004. 
DECKELBAUM RJ, WORGALL TS, SEO T: n3 Fatty acids and gene expression. Am J Clin Nutr 83: 1520-1525, 2006.

DEN RUIJTER HM, BERECKI G, OPTHOF T, VERKERK AO, ZOCK PL, CORONEL R: Pro- and antiarrhythmic properties of diet rich in fish oil. Cardiovasc Res 73: 316-325, 2007.

DENG WG, TANG ST, TSENG HP, WU KK: Melatonin suppresses macrophage cyclooxygenase-2 and inducible nitric oxide synthase expression by inhibiting p52 acetylation and binding. Blood 108: 518-524, 2006.

DIAMOND JA, PHILLIPS RA: Hypertensive heart disease. Hypertens Res 28: 191-202, 2005.

DIEZ ER, RENNA NF, PRADO NJ, LEMBO C, PONCE ZUMINO AZ, VAZQUEZ-PRIETO M, MIATELLO RM: Melatonin, given at the time of reperfusion, prevents ventricular arrhythmias in isolated hearts from fructosefed rats and spontaneously hypertensive rats. J Pineal Res 55: 166-173, 2013.

DIEZ ER, ALTAMIRANO LB, GARCÍA IM, MAZZEI L, PRADO NJ, FORNES MW, CARRIÓN FD, ZUMINO AZ, FERDER L, MANUCHA W: Heart remodeling and ischemia-reperfusion arrhythmias linked to myocardial vitamin D receptors deficiency in obstructive nephropathy are reversed by paricalcitol. $J$ Cardiovasc Pharmacol Ther 20: 211-220, 2015.

DOBSAK P, SIEGELOVA J, EICHER JC, JANCIK J, SVACINOVA H, VASKU J, KUCHTICKOVA S, HORKY M, WOLF JE: Melatonin protects against ischemia-reperfusion injury and inhibits apoptosis in isolated working rat heart. Pathophysiology 9: 179-187, 2003.

DOMINGUEZ-RODRIGUEZ A, ABREU-GONZALES P, SANCHEZ-SANCHEZ JJ, KASKI JC, REITER RJ: Melatonin and circadian biology in human cardiovascular disease. $J$ Pineal Res 49: 14-22, 2010.

EDEM DO: Palm oil: biochemical, physiological, nutritional, hematological, and toxicological aspects: a review. Plant Foods Hum Nutr 57: 319-341, 2002.

EDEM DO: Haematological and histological alterations induced in rats by palm oil-containing diets. Eur J Sci Res 32: 405-518, 2009.

ENDO J, ARITA M: Cardioprotective mechanism of omega-3 polyunsaturated fatty acids. J Cardiol 67: 22-27, 2016.

ENGELBRECHT AM, ESTERHUYSE J, DU TOIT EF, LOCHNER A, VAN ROOYEN J: p38-MAPK and PKB/Akt, possible role players in red palm oil-induced protection of the isolated perfused rat heart? J Nutr Biochem 17: 265-271, 2006.

ENGELBRECHT AM, ODENDAAL L, DU TOIT EF, KUPAI K, CSONT T, FERDINANDY P, VAN ROOYEN J: The effect of dietary red palm oil on the functional recovery of the ischaemic/reperfused isolated rat heart: the involvement of the PI3-kinase signaling pathway. Lipids Health Dis 8: 18, 2009.

ESTERHUYSE JS, VAN ROOYEN J, STRIJDOM H, BESTER D, DU TOIT EF: Proposed mechanisms for red palm oil induced cardioprotection in a model of hyperlipidaemia in the rat. Prostaglandins Leukot Essent Fatty Acids 75: 375-384, 2006.

FISCHER R, DECHEND R, QADRI F, MARKOVIC M, FELDT S, HERSE F, PARK JK, GAPELYUK A, SCHWARZ I, ZACHARZOWSKY UB, PLEHM R, SAFAK E, HEUSER A, SCHIRDEWAN A, LUFT FC, SCHUNCK WH, MULLER DN: Dietary n-3 polyunsaturated fatty acids and direct renin inhibition improve electrical remodeling in a model of high human renin hypertension. Hypertension 51: 540-546, 2008.

FONTES MS, VAN VEEN TA, DE BAKKER JM, VAN RIJEN HV: Functional consequences of abnormal Cx43 expression in the heart. Biochim Biophys Acta 1818: 2020-2029, 2012.

GROSSMAN E, LAUDON M, YALCIN R, ZENGIL H, PELEG E, SHARABI Y, KAMARI Y, SHEN-ORR Z, ZISAPEL N: Melatonin reduces night blood pressure in patients with nocturnal hypertension. Am J Med 119: 898-902, 2006.

HILL JA: Electrical remodeling in cardiac hypertrophy. Trends Cardiovasc Med 13: 316-322, 2003.

HIROOKA Y: Oxidative stress in the cardiovascular center has a pivotal role in the sympathetic activation in hypertension. Hypertens Res 34: 407-412, 2011.

JONAS M, GARFINKEL D, ZISAPEL N, LAUDON M, GROSSMAN E: Impaired nocturnal melatonin secretion in non-dipper hypertensive patients. Blood Press 12: 19-24, 2003.

KANEKO S, OKUMURA K, NUMAGUCHI Y, MATSUI H, MURASE K, MOKUNO S, MORISHIMA I, HIRA K, TOKI Y, ITO T, HAYAKAWA T: Melatonin scavenges hydroxyl radical and protects isolated rat hearts from ischemic reperfusion injury. Life Sci 67: 101-112, 2000. 
KEDZIORA-KORNATOWSKA K, SZEWCZYK-GOLEC K, CZUCZEJKO J, VAN MARKE DE LUMEN K, PAWLUK H, MOTYL J, KARASEK M, KEDZIORA J: Effect of melatonin on the oxidative stress in erythrocytes of healthy young and elderly subjects. J Pineal Res 42: 153-158, 2007.

KEDZIORA-KORNATOWSKA K, SZEWCZYK-GOLEC K, CZUCZEJKO J, PAWLUK H, VAN MARKE DE LUMEN K, KOZAKIEWICZ M, BARTOSZ G, KEDZIORA J: Antioxidative effects of melatonin administration in elderly primary essential hypertension patients. J Pineal Res 45: 312-317, 2008.

KOSTIN S, DAMMER S, HEIN S: Connexin 43 expression and distribution in compensated and decompensated cardiac hypetrophy in patients with aortic stenosis. Cardiovasc Res 62: 426-436, 2004.

KUNES J, ZICHA J: The interaction of genetic and environmental factors in the etiology of hypertension. Physiol Res 58: 33-41, 2009.

KUNEŠ J, VANĚČKOVÁ I, MIKULÁŠKOVÁ B, BEHULIAK M, MALETÍNSKÁ L, ZICHA J: Epigenetics and a new look on metabolic syndrome. Physiol Res 64: 611-620, 2015.

LEE YM, CHEN HR, HSIAO G, SHEU JR, WANG JJ, YEN MH: Protective effects of melatonin on myocardial ischemia/reperfusion injury in vivo. J Pineal Res 33: 72-80, 2002.

LORELL BH, CARABELLO BA: Left ventricular hypertrophy: pathogenesis, detection, and prognosis. Circulation 102: 470-479, 2000.

MAJZUNOVA M, DOVINOVA I, BARANCIK M, CHAN JY: Redox signaling in pathophysiology of hypertension. J Biomed Sci 20: 69, 2013.

MARCHIOLI R, MARFISI RM, BORRELLI G, CHIEFFO C, FRANZOSI MG, LEVANTESI G, MAGGIONI AP, NICOLOSI GL, SCARANO M, SILLETTA MG, SCHWEIGER C, TAVAZZI L, TOGNONI G: Efficacy of n-3 polyunsaturated fatty acids according to clinical characteristics of patients with recent myocardial infarction: insights from the GISSI-Prevenzione trial. J Cardiovasc Med (Hagerstown) 8: 34-37, 2007.

MITCHELL JA, LYE SJ: Regulation of connexin 43 expression by c-fos and c-jun in myometrial cells. Cell Commun Adhes 8: 299-302, 2001.

MOŻDŻAN M, MOŻDŻAN M, CHAŁUBIŃSKI M, WOJDAN K, BRONCEL M: The effect of melatonin on circadian blood pressure in patients with type 2 diabetes and essential hypertension. Arch Med Sci 4: 669-675, 2014.

NAIR SS, LEITCH JW, FALCONER J, GARG ML: Prevention of cardiac arrythmia by dietary (n-3) polyunsaturated fatty acids and their mechanism of action. J Nutr 127: 383-393, 1997.

PAULIS L, SIMKO F, LAUDON M: Cardiovascular effects of melatonin receptor agonists. Expert Opin Investig Drugs 21: 1661-1678, 2012.

RADOSINSKA J, BACOVA B, KNEZL V, BENOVA T, ZURMANOVA J, SOUKUP T, ARNOSTOVA P, SLEZAK J, GONÇALVESOVA E, TRIBULOVA N: Dietary omega-3 fatty acids attenuate myocardial arrhythmogenic factors and propensity of the heart to lethalarrhythmias in a rodent model of human essential hypertension. J Hypertens 31: 1876-1885, 2013.

RAUCH B, SENGES J: The effects of supplementation with omega-3 polyunsaturated fatty acids on cardiac rhythm: anti-arrhythmic, pro-arrhythmic, both or neither? It depends... Front Physiol 3: 57, 2012.

RECHCIŃSKI T, TRZOS E, WIERZBOWSKA-DRABIK K, KRZEMIŃSKA-PAKULA M, KURPESA M: Melatonin for nondippers with coronary artery disease: assessment of blood pressure profile and heart rate variability. Hypertens Res 33: 56-61, 2010.

REIFFEL JA, MCDONALD A: Antiarrhythmic effects of omega-3 fatty acids. Am J Cardiol 21: 50i-60i, 2006.

REITER RJ: The pineal gland and melatonin in relation to aging: a summary of the theories and of the data. Exp Gerontol 30: 199-212, 1995.

REITER RJ, TAN DX, GALANO A: Melatonin: exceeding expectations. Physiology (Bethesda) 29: 325-333, 2014.

RICHARDSON ES, IAIZZO PA, XIAO YF: Electrophysiological mechanisms of the anti-arrhythmic effects of omega-3 fatty acids. J Cardiovasc Transl Res 4: 42-52, 2011.

RIZOS EC, NTZANI EE, BIKA E, KOSTAPANOS MS, ELISAF MS: Association between omega-3 fatty acid supplementation and risk of major cardiovascular disease events: a systematic review and meta-analysis. JAMA 308: 1024-1033, 2012. 
RODRIGO R, GONZÁLEZ J, PAOLETTO F: The role of oxidative stress in the pathophysiology of hypertension. Hypertens Res 34: 431-440, 2011.

SAHNA E, ACET A, OZER MK, OLMEZ E: Myocardial ischemia-reperfusion in rats: reduction of infarct size by either supplemental physiological or pharmacological doses of melatonin. J Pineal Res 33: 324-328, 2002a.

SAHNA E, OLMEZ E, ACET A: Effects of physiological and pharmacological concentrations of melatonin on ischemiareperfusion arrhythmias in rats: can the incidence of complete sudden cardiac death be reduced? J Pineal Res 32: 194-198, 2002b.

SCHEER FA, VAN MONTFRANS GA, VAN SOMEREN EJ, MAIRUHU G, BUIJS RM: Daily nighttime melatonin reduces blood pressure in male patients with essential hypertension. Hypertension 43: 192-197, 2004.

SEWERYNEK E: Melatonin and the cardiovascular system. Neuro Endocrinol Lett 23: 79-83, 2002.

SHARKEY JT, PUTTARAMU R, WORD RA, OLCESE J: Melatonin synergizes with oxytocin to enhance contractility of human myometrial smooth muscle cells. J Clin Endocrinol Metab 94: 421-427, 2009.

SIMKO F, PAULIS L: Melatonin as a potential antihypertensive treatment. J Pineal Res 42: 319-322, 2007.

SIMKO F, PECHANOVA O: Recent trends in hypertension treatment: perspectives from animal studies. $J$ Hypertens 27: 1-4, 2009.

SIMKO F, PECHANOVA O, REPOVA BEDNAROVA K, KRAJCIROVICOVA K, CELEC P, KAMODYOVA N, ZORAD S, KUCHARSKA J, GVOZDJAKOVA A, ADAMCOVA M, PAULIS L: Hypertension and cardiovascular remodelling in rats exposed to continuous light: protection by ACE-inhibition and melatonin. Mediators Inflamm 2014: 703175, 2014.

SMYTH JW, HONG TT, GAO D, VOGAN JM, JENSEN BC, FONG TS, SIMPSON PC, STAINIER DY, CHI NC, SHAW RM: Limited forward trafficking of connexin 43 reduces cell-cell coupling in stressed human and mouse myocardium. J Clin Invest 120: 266-279, 2010.

SOVARI AA, RUTLEDGE CA, JEONG EM, DOLMATOVA E, ARASU D, LIU H, VAHDANI N, GU L, ZANDIEH S, XIAO L, BONINI MG, DUFFY HS, DUDLEY SC JR: Mitochondria oxidative stress, connexin43 remodeling, and sudden arrhythmic death. Circ Arrhythm Electrophysiol 6: 623-631, 2013.

SZARSZOI O, ASEMU G, VANECEK J, OSTADAL B, KOLAR F: Effects of melatonin on ischemia and reperfusion injury of the rat heart. Cardiovasc Drugs Ther 5: 251-257, 2001.

SZUCS G, BESTER DJ, KUPAI K, CSONT T, CSONKA C, ESTERHUYSE AJ, FERDINANDY P, VAN ROOYEN J: Dietary red palm oil supplementation decreases infarct size in cholesterol fed rats. Lipids Health Dis 10: 103, 2011.

TEUNISSEN BEJ, JONGSMA HJ, BIERHUIZEN MFA: Regulation of myocardial connexins during hypertrophic remodelling. Eur Heart J 25: 1979-1989, 2004.

TRIBULOVA N, OKRUHLICOVA L, IMANAGA I, HIROSAWA N, OGAWA K, WEISMANN P: Factors involved in the susceptibility of spontaneously hypertensive rats to low K+-induced arrhythmias. Gen Physiol Biophys 22: 369-382, 2003.

TRIBULOVA N, SZEIFFOVA BACOVA B, BENOVA T, VICZENCZOVA C: Can we protect from malignant arrhythmias by modulation of cardiac cell-to-cell coupling? J Electrocardiol 48: 434-440, 2015.

VAN ROOYEN J, ESTERHUYSE AJ, ENGELBRECHT AM, DU TOIT EF: Health benefits of a natural carotenoid rich oil: a proposed mechanism of protection against ischaemia/reperfusion injury. Asia Pac J Clin Nutr 17: 316-319, 2008.

WOLF G: Free radical production and angiotensin. Curr Hypert Res 2: 167-173, 2000.

XU HF, DING YJ, SHEN YW, XUE AM, XU HM, LUO CL, LI BX, LIU YL, ZHAO ZQ: MicroRNA-1 represses Cx43 expression in viral myocarditis. Mol Cell Biochem 362: 141-148, 2012.

YANG B, LIN H, XIAO J, LU Y, LUO X, LI B, ZHANG Y, XU C, BAI Y, WANG H, CHEN G, WANG Z: The muscle-specific microRNA miR-1 regulates cardiac arrhythmogenic potential by targeting GJA1 and KCNJ2. Nat Med 13: 486-491, 2007.

YANG KC, BONINI MG, DUDLEY SC JR: Mitochondria and arrhythmias. Free Radic Biol Med 71: 351-361, 2014.

ZANCHETTI A: Is hypertension a fatal disease today? J Hypertens 29 (Suppl 1): S1, 2011.

ZEMAN M, DULKOVÁ K, BADA V, HERICHOVÁ I: Plasma melatonin concentrations in hypertensive patients with the dipping and non-dipping blood pressure profile. Life Sci 76: 1795-1803, 2005. 
ZHAO Y, RANSOM JF, LI A, VEDANTHAM V, VON DREHLE M, MUTH AN, TSUCHIHASHI T, MCMANUS MT, SCHWARTZ RJ, SRIVASTAVA D: Dysregulation of cardiogenesis, cardiac conduction, and cell cycle in mice lacking miRNA-1-2. Cell 129: 303-317, 2007.

ZICHA J, BEHULIAK M, PINTÉROVÁ M, BENCZE M, KUNEŠ J, VANĚČKOVÁ I: The interaction of calcium entry and calcium sensitization in the control of vascular tone and blood pressure of normotensive and hypertensive rats. Physiol Res 63 (Suppl 1): S19-S27, 2014. 